University of South Carolina

Scholar Commons

$11-2007$

\title{
Associations among Physical Activity, Health Indicators, and Employment in 12th Grade Girls
}

\author{
Marsha Dowda \\ University of South Carolina - Columbia, mdowda@mailbox.sc.edu \\ Karin A. Pfeiffer \\ Rod K. Dishman \\ Russell R. Pate \\ University of South Carolina - Columbia, rpate@mailbox.sc.edu
}

Follow this and additional works at: https://scholarcommons.sc.edu/

sph_physical_activity_public_health_facpub

Part of the Public Health Commons

\section{Publication Info}

Published in Journal of Women's Health, Volume 16, Issue 9, 2007, pages 1331-1339.

Dowda, M., Pfeiffer, K. A., Dishman, R. K., \& Pate, R. R. (2007). Associations among physical activity, health indicators, and employment in 12th grade girls. Journal of Women's Health, 16(9), 1331-1339.

DOI: $10.1089 /$ jwh.2006.0302

(c) Journal of Women's Health, 2007, Mary Ann Liebert, Inc.

This Article is brought to you by the Physical Activity and Public Health at Scholar Commons. It has been accepted for inclusion in Faculty Publications by an authorized administrator of Scholar Commons. For more information, please contact digres@mailbox.sc.edu. 


\title{
Associations among Physical Activity, Health Indicators, and Employment in 12th Grade Girls
}

\author{
MARSHA DOWDA, Dr.P.H., ${ }^{1}$ KARIN A. PFEIFFER, Ph.D., ${ }^{2}$ \\ ROD K. DISHMAN, Ph.D. ${ }^{3}$ and RUSSELL R. PATE, Ph.D. ${ }^{1}$
}

\begin{abstract}
Objectives: This study compared physical activity, sedentary behaviors, and other health indicators between 1381 employed and nonemployed 12th grade girls.

Methods: The girls were from 22 high schools in South Carolina (2002-2003); 56\% of the girls were African American, and the mean age was $17.7(0.6)$ years. Physical activity and sedentary behaviors were measured using the 3-Day Physical Activity Recall (3DPAR). Fitness, depressive symptoms, and smoking behavior were assessed.

Results: Fifty percent of the girls were employed, and on average, employed girls worked 9.6 30-minute blocks per day. Girls who worked reported significantly ( $p \leq 0.001)$ higher average total metabolic equivalents (METs) (mean [M] 66.4, SE 0.5) than girls who did not work (M 59.5, SE 0.5). Also, a higher percent of girls who worked reported 2+ blocks of moderate to vigorous physical activity (MVPA) $(89.3 \%)$, and fewer $(20.2 \%)$ reported $4+$ blocks of electronic media (EM) compared with girls who did not work (MVPA 62.7\%, EM 41.7\%). After on-the-job activity was subtracted, total METs for girls who worked was reduced to 48.0 (SE 0.4 ), and only $48.5 \%$ reported 2 or more blocks on average of MVPA. No significant differences $(p>0.05)$ were found between girls who reported working $(W)$ and those who did not (NW) for body mass index (BMI) (W: M 25.2, SE 0.2; NW: M 24.6, SE 0.2), depression scores (W: M 14.4, SE 0.5; NW: M 14.4, SE 0.5), fitness (W: M $11.3 \mathrm{~kg} \cdot \mathrm{m} / \mathrm{min} / \mathrm{kg}$, SE 0.2; NW: M 11.7 $\mathrm{kg} \cdot \mathrm{m} / \mathrm{min} / \mathrm{kg}$, SE 0.2 ), or smoking during the past 30 days (W: $18.5 \% ; \mathrm{NW}: 17.4 \%$ ).

Conclusions: Nearly one third of employed high school girls' total physical activity occurred while they were at work. Employed girls also spent less time using electronic media. Employment was not associated with fitness, smoking, or depressive symptoms in 12th grade girls.
\end{abstract}

\section{INTRODUCTION}

$\mathbf{Y}$ OUTH EMPLOYMENT RATES in the United States have increased since the 1970s. Nationally, the employment rate among 16-year-old and 17-year- old female high school students is approximately $30 \%,{ }^{1}$ and older students are more likely to be employed than younger students. From 1996 to 1998, girls aged 15-17 who had jobs worked an average of 16 hours per week during the school year. ${ }^{2}$

\footnotetext{
${ }^{1}$ Department of Exercise Science, Arnold School of Public Health, University of South Carolina, Columbia, South Carolina.

${ }^{2}$ Department of Kinesiology, Michigan State University, East Lansing, Michigan.

${ }^{3}$ Department of Exercise Science, University of Georgia, Athens, Georgia.

This study was funded by National Heart, Lung and Blood Institute grant NIH HL 59775.
} 
Several studies indicate that youth who work during the school year may be at risk for negative health and social behaviors. For example, employment has been associated with substance abuse in high school girls. ${ }^{3-6}$ Also, employed high school students cut more classes and are less likely to take part in extracurricular activities. ${ }^{7} \mathrm{On}$ the other hand, it has been suggested that money obtained through employment may provide teenagers with the resources needed to participate in physical activities they otherwise could not afford, ${ }^{8}$ and young people who work during high school may adapt better to full-time work after they graduate than those who do not. ${ }^{6}$

During high school, girls' participation in leisure time physical activity and sports declines significantly. ${ }^{9}$ During the same period, the percent of girls who are employed increases. ${ }^{2,10} \mathrm{Em}$ ployed high school girls are most likely to work as food preparers or servers (26\%), cashiers (24\%), or other sales positions $(13 \%),{ }^{10}$ all of which involve light to moderate physical activity. Little is known about whether there are differences in physical activity levels, sedentary behaviors, and other health-related factors between employed and nonemployed high school girls. Therefore, the purpose of this study was to compare employed and nonemployed 12th grade girls in terms of physical activity, sedentary behaviors, and other health indicators.

\section{MATERIALS AND METHODS}

\section{Subjects and settings}

Subjects were 12th grade girls attending 22 high schools in South Carolina in 2002-2003. The schools had previously participated in a physical activity intervention study, and equal numbers of schools had been in intervention and control groups. ${ }^{11}$ A total of 1594 girls provided data as 12th graders After deleting girls with races other than African American or white $(n=63)$ and those missing physical activity $(n=95)$ or body mass index (BMI) $(n=55)$ information, data from 1381 girls were available for analyses. A higher percent of the excluded girls were white and reported employment than the girls included in the study (Table 1). Fifty-seven percent of the girls attended schools in the intervention group. In this analysis sample, $74 \%$ of girls in the intervention schools and $77 \%$ in the control schools had at- tended the same high schools when the intervention was implemented in the 9th grade. Each participating girl and her parent or guardian (for girls $<18$ years of age) provided written informed consent. Study procedures were approved by the University of South Carolina Institutional Review Board.

\section{Study design and data collection procedures}

A cross-sectional study design was used in comparing 12th grade girls who were employed with their nonemployed counterparts. Measures of physical activity, physical fitness, sedentary behavior, other health behaviors, and anthropometric characteristics were administered by trained data collectors using standardized scripts and protocols. Each girl was seen over several visits during a single week in the spring of her 12th grade year. Data were collected during the school day with groups of 20-30 girls.

\section{3-Day Physical Activity Recall}

The 3-Day Physical Activity Recall (3DPAR) was used to measure participation in physical activity and other activities. This instrument, a modification of the Previous Day Physical Activity Recall (PDPAR), has been shown in previous studies to be valid and reliable. ${ }^{12}$ In a validity study, vigorous physical activity (VPA) as measured by the 3DPAR was correlated $(r=0.41, p<$ 0.001 ) with log transformed VPA measured by accelerometry in 708 th and 9 th grade girls $(54.3 \%$ white, $37.1 \%$ African American). ${ }^{13}$ The 3DPAR uses a script and graphic figures to explain the intensity level of common activities. Light activities are described as requiring little or no movement with slow breathing, moderate activities as requiring some movement and normal breathing, hard activities as requiring moderate movement and increased breathing, and very hard activities as requiring quick movements and hard breathing.

The 3DPAR was always administered on a Wednesday, with subjects being asked to recall their activities on the previous 3 days (first Tuesday, then Monday, then Sunday). Girls completed a grid for each day recalled. The grid was divided into 30-minute time blocks, beginning at $7 \mathrm{AM}$ and ending at 12 midnight. The girls were asked to report the predominant activity performed during each of the 30-minute blocks. A 
list of 59 activities was provided that included sedentary activities, activities of daily living, physical activities, job, physical education, and sports. For each time block, girls entered the number of an activity and indicated if the activity was performed at a light, moderate, hard, or very hard intensity.

Data across the 3 days were reduced to total metabolic equivalent (MET) blocks per day. Also, girls were categorized on the basis of meeting or not meeting two physical activity standards. Girls met the first standard if they reported an average of 2 or more 30-minute blocks of moderate to vigorous physical activity (MVPA, $\geq 3$ METs) and met the second standard if they reported an average of 1 or more 30-minute blocks of vigorous physical activity (VPA, $\geq 6$ METs) per day. MET values for the intensity level of each activity were obtained from the Compendium of Physical Activities ${ }^{14}$; 1 MET is defined as the ratio of the activity metabolic rate to the resting metabolic rate. In addition, the average number of 30-minute blocks spent doing homework was calculated.

Girls who reported working on the 3DPAR were considered to be the employed group, and others were considered to be nonemployed. Girls who reported work were also asked to list their type of employment on the 3DPAR.

A second set of variables was created after eliminating work-related physical activity and included total nonwork MET blocks per day, nonwork MVPA, and nonwork VPA. In order to represent sedentary behaviors, the reported average number of blocks per day of electronic media (EM) use (TV, videos, computer games, and Internet) was dichotomized into 4 or fewer or more than 4. This categorization was based on the recommendation of the American Academy of Pediatrics that young people limit EM to a maximum of 2 hours/day. ${ }^{15,16}$

\section{Accelerometry data}

A subset of girls wore an ActiGraph accelerometer (ActiGraph, MTI model 7164, Fort Walton Beach, FL) for 7 days. A total of 325 girls provided data for at least 3 weekdays and 1 weekend day. The girls who wore the monitor were comparable to the total sample in age, self-reported total METs per day, percent African American, percent with a parent with greater than a high school education, and employment status. However, proportionately more of the girls who wore the accelerometer were from the control schools than from the intervention schools (Table 1).

Accelerometry data were collected in 1-minute increments. The ActiGraph was worn at the waist over the right hip, attached to an elastic belt. The girls were asked to remove the monitor only when swimming, bathing, or sleeping. The data were summarized by a SAS Macro computer program using age-specific cut points for physical activity intensity. ${ }^{17}$ If more than 20 continuous minutes of zero counts were detected, those minutes were considered missing. On average, girls wore the monitors for 11 hours per day. Summary variables included daily minutes of sedentary, light, MVPA, and VPA per day.

\section{Other self-reported variables}

Sports participation was assessed using two questions adapted from the Youth Risk Behavior Surveillance survey. ${ }^{9}$ The first question was: During the past 12 months, how many sports teams operated by your school did you play on? The second question asked about teams operated by organizations outside of school. If a girl reported participating on one or more sports teams of either type, she was considered a sports participant.

Girls completed the Center for Epidemiologic Studies-Depression (CES-D) scale, which consists of 20 items that measure depressive symptoms. ${ }^{18}$ Each item is rated on a $0-3$ scale based on the frequency of occurrence during the past week $(0=<1$ day; $1=1-2$ days; $2=3-4$ days; $3=5-7$ days). Possible scores range from 0 to 60 , with higher scores indicating greater depressive symptoms.

Other questions were used to ascertain socioeconomic status and smoking status. Parent education was used as an indicator of socioeconomic status. The highest education level reported for either parent was dichotomized into less than or equal to a high school education and greater than a high school education. Girls were classified as smokers or nonsmokers based on whether they reported cigarette smoking during the past 30 days. ${ }^{9}$

\section{Body mass index}

Height was measured to the nearest $0.2 \mathrm{~cm}$ with a portable stadiometer, and weight was measured to the nearest $0.1 \mathrm{~kg}$ with a digital scale 
(BeFour Inc., Saukville, WI). BMI was calculated by dividing weight in kilograms by height in meters squared.

\section{Fitness}

Aerobic fitness was measured using a modified version of the Physical Work Capacity 170 test (PWC170). ${ }^{19}$ Research assistants followed a standard protocol designed to elicit heart rates of 120 , 150 , and 170 beats per minute (bpm) at the end of each of three 2-minute exercise stages (6 minutes total). ${ }^{20,21}$ Students with a heart rate $<160$ bpm at the end of the third stage performed a fourth stage to bring their heart rate to approximately $170 \mathrm{bpm}$. Each student was fitted with a Polar heart rate monitor (Polar USA, Inc., Lake Success, NY), which was used to assess her heart rate during the final 10 seconds of each stage. For all participants, a common resistance $(0.5 \mathrm{Kp})$ was used for the first stage. The linear association between workload and heart rate was confirmed by calculating the $R^{2}$ and only including tests with an $R^{2}>0.90$. Heart rate responses were individually extrapolated to the workload eliciting 170 bpm and are reported in absolute terms $(\mathrm{kg}$ $\mathrm{M} / \mathrm{min}$ ) and relative to body weight $(\mathrm{kg} \cdot \mathrm{m} /$ $\mathrm{min} / \mathrm{kg}$ body weight).

\section{Statistical analyses}

Means (SD) and percents were calculated for demographic variables for the total sample and for the subset that wore an accelerometer. Chisquare analyses were used to determine if girls differed in terms of race, parent education, school location (rural vs. suburban, urban) by employment status. For girls who reported employment, the mean number of daily 30-minute blocks of employment and the percent of girls who reported working on 1,2, or 3 days were calculated. Frequencies of type of employment that girls reported were determined. Mixed model analysis of variance models with school nested in group as a random variable were used to determine if the physical activity (both self-reported and objectively measured), sedentary behaviors, and health-related variables differed by employment status. Both total sample and race-specific models were calculated, controlling for group (control vs. intervention), race, and BMI. Mixed model analysis was conducted to determine if girls who worked $\geq 1030$-minute blocks differed in healthrelated variables from employed girls who worked $<10$ 30-minute blocks.

\section{RESULTS}

Mean age of the participants was 17.7 (SD 0.6) years, and $56 \%$ of the girls were African American (Table 1$)$. About $50 \%(n=689)$ of the girls reported working on at least 1 of the 3 days for which they reported their activities. A greater percentage of white girls $(52.9 \%)$ than African American girls $(47.6 \%)$ reported employment, and the difference approached statistical significance $(p=0.06)$ after controlling for group (control vs. intervention) and with school as a random variable. In similar analyses, no differences $(p=0.83)$ were found in the percent of girls who

Table 1. Characteristics of Total Sample: 1381 Girls in Study Sample and Subset with Accelerometer Data

\begin{tabular}{lccc}
\hline & \multicolumn{3}{c}{ Mean (SD) or \% } \\
\cline { 2 - 4 } Characteristic & $\begin{array}{c}\text { Total sample } \\
(\mathrm{n}=1594)\end{array}$ & $\begin{array}{c}\text { Study sample } \\
(\mathrm{n}=1381)\end{array}$ & $\begin{array}{c}\text { Subset }^{\mathrm{b}} \\
(\mathrm{n}=325)\end{array}$ \\
\hline Age, years & $17.7(0.6)$ & $17.7(0.6)$ & $17.7(0.6)$ \\
Total METs & $61.8(12.1)$ & $62.9(12.1)$ & $63.8(12.5)$ \\
African American & $55.3 \%$ & $56.1 \%$ & $52.0 \%$ \\
Parent education & $62.9 \%$ & $63.5 \%$ & $63.4 \%$ \\
$\quad \begin{array}{l}> \\
\text { Employed }\end{array}$ & $50.1 \%$ & $49.9 \%$ & $49.9 \%$ \\
Rural area & $43.0 \%$ & $43.7 \%$ & $48.9 \%$ \\
Control group & $43.9 \%$ & $43.5 \%$ & $59.7 \%$ \\
\hline
\end{tabular}

${ }^{a} n$ varies from 1594 to 1381.

${ }^{b}$ Girls who wore accelerometers. 
were employed for those whose parents had a high school education or less (50.3\%) and those whose parents had greater than a high school education $(49.7 \%)$, nor were differences found in the percent of girls who were employed $(p=0.37)$ in rural $(47.9 \%)$ or in urban areas $(51.4 \%)$. Girls who worked reported an average of 9.6 (SD 3.8) 30minute blocks of work per day. Of the girls who worked, approximately $20 \%$ worked on all 3 days of the recall, and about $28 \%$ began working before the end of the school day. One third of the girls worked in restaurants or fast food establishments, $14 \%$ reported being a cashier, and $13 \%$ reported providing child care or babysitting.

Table 2 presents self-reported physical activity variables by employment status for each race group and for the total sample. Employed girls reported higher physical activity. However, when activity reported during work was deleted, nonemployed girls had higher physical activity. Similar patterns were observed in white and African American girls for total METs and MVPA. However, there was no difference by employment status in the percent of white girls who reported 1 or more blocks of VPA per day when total activity was considered. Similarly, no difference by employment status was found for 1 or more blocks of VPA per day after deleting activity accumulated while at work among African American girls.

Table 3 presents the physical activity variables measured by accelerometry in a subset of 325 girls. The only difference detected by employment status was for light activity. Girls who were employed accumulated significantly more minutes of light activity per day $(p<0.01)$ than did girls who were not employed. Girls who were employed also accumulated more minutes of MVPA and VPA than girls who were not, although the differences were not statistically significant.

Tables 4 and 5 present sedentary and health variables by employment status. A higher percent of girls who were not employed reported 4 or more 30-min blocks of EM per day compared with girls who were employed $(p<0.001)$. Nonemployed girls in the total group reported more 30-min blocks of homework than did employed girls $(p<0.01)$. However, among African American girls, there was no difference in reported homework. There were no differences by employment status for BMI, depressive symptoms, fitness, smoking, or sport participation in the past year.

Table 2. Self-Reported Physical Activity Variables a by Employment Status

\begin{tabular}{lrrr}
\hline Variable & Nonemployed & Employed & $\mathrm{p}$ \\
\hline Total group $n=1381^{\mathrm{b}}$ & & & \\
Total METs & $59.5(0.5)$ & $66.4(0.5)$ & $<0.001$ \\
$2+$ blocks MVPA & $62.7 \%(1.6)$ & $89.3(1.6)$ & $<0.001$ \\
$1+$ block VPA & $32.9 \%(2.6)$ & $39.8 \%(2.0)$ & 0.01 \\
Nonwork total METs & $59.7(0.4)$ & $48.0(0.4)$ & $<0.001$ \\
Nonwork 2+ blocks MVPA & $63.3 \%(2.0)$ & $48.5 \%(2.0)$ & $<0.001$ \\
Nonwork 1+ block VPA & $33.3 \%(2.0)$ & $27.5 \%(2.0)$ & 0.02 \\
White $(n=606)^{c}$ & & & \\
Total METs & $61.8(0.7)$ & $65.7(0.7)$ & $<0.001$ \\
$2+$ blocks MVPA & $70.0 \%(2.7)$ & $90.0 \%(2.6)$ & $<0.001$ \\
1+ block VPA & $43.2 \%(3.2)$ & $42.4 \%(3.1)$ & 0.86 \\
Nonwork total METs & $61.8(0.7)$ & $50.1(0.6)$ & $<0.001$ \\
Nonwork 2+ blocks MVPA & $70.0 \%(3.2)$ & $55.3 \%(3.0)$ & $<0.001$ \\
Nonwork 1+ block VPA & $43.3 \%(3.2)$ & $34.6 \%(3.1)$ & 0.03 \\
African American $(n=775)^{c}$ & & & \\
Total METs & $57.8(0.6)$ & $67.1(0.7)$ & $<0.001$ \\
$2+$ blocks MVPA & $57.2 \%(2.1)$ & $88.9 \%(2.2)$ & $<0.001$ \\
1+ block VPA & $24.5 \%(2.7)$ & $37.4 \%(2.8)$ & $<0.001$ \\
Nonwork total METs & $57.9(0.6)$ & $46.0(0.6)$ & $<0.001$ \\
Nonwork 2+ blocks MVPA & $57.7 \%(2.6)$ & $42.4 \%(2.8)$ & $<0.001$ \\
Nonwork 1+ block VPA & $24.9 \%(2.5)$ & $21.0 \%(2.6)$ & 0.20 \\
\hline
\end{tabular}

${ }^{\mathrm{a}}$ Mean or \% (SE).

${ }^{\mathrm{b}}$ Mixed analyses, controlling for group, race, BMI, with school as a random variable.

'Mixed analyses, controlling for group, BMI, with school as a random variable. 
Table 3. Mean (SE) Physical Activity Variables FROM ACCELEROMETER by EMPLOYMENT STATUS

\begin{tabular}{lcrr}
\hline Variable & Nonemployed & Employed & p value \\
\hline & Minutes per day & & \\
Total $(n=325)^{\mathrm{a}}$ & & & \\
Sedentary & $426.8(13.6)$ & $413.9(13.7)$ & 0.46 \\
Light & $226.5(10.2)$ & $259.4(10.3)$ & $<0.01$ \\
MVPA & $21.5(1.4)$ & $23.1(1.4)$ & 0.29 \\
VPA & $1.3(0.2)$ & $1.5(0.2)$ & 0.40 \\
White $(n=156)^{\mathrm{c}}$ & & & \\
Sedentary & $416(19.6)$ & $400.4(19.3)$ & 0.49 \\
Light & $215.6(15.0)$ & $253.1(14.9)$ & 0.01 \\
MVPA & $22.4(2.3)$ & $25.4(2.3)$ & 0.17 \\
VPA & $1.7(0.4)$ & $2.0(0.4)$ & 0.67 \\
African American $(n=169)^{\mathrm{c}}$ & & & \\
Sedentary & $443.2(17.9)$ & $430.2(18.9)$ & 0.62 \\
Light $_{\text {MVPA }}$ & $239.2(13.2)$ & $269.6(13.8)$ & 0.08 \\
VPA & $20.6(1.3)$ & $20.9(1.4)$ & 0.88 \\
\hline
\end{tabular}

${ }^{a}$ Mixed analyses, controlling for group, race, BMI, with school as a random variable. ${ }^{b}$ Log transformed for analysis and untransformed means (SE) reported.

'Mixed analyses, controlling for group and BMI, with school as a random variable.

In separate analyses, girls in the present study who reported working $\leq 1030$-minute blocks per day were compared with girls who reported working $>10$ blocks per day on average over the 3-day period (data not shown). There were no differences between the groups in percent of girls who smoked or participated in sports during the past year or in mean BMI, CES-D, or fitness.

\section{DISCUSSION}

This study is unique in that both self-reported and objectively collected data were used to investigate differences in physical activity levels of employed and nonemployed girls. Employed girls self-reported higher total METs and were more likely to participate in 2 or more blocks of MVPA and 1 or more blocks of VPA per day than nonemployed girls. The accelerometry data indicated that girls who worked accumulated significantly more light activity, and there was a tendency for them to accumulate more MVPA than those who did not work. Previous studies have had inconsistent findings regarding the relationship between employment and leisure time activity. Feldman et al. ${ }^{8}$ reported that leisure time physical activity was positively associated with part-time work. Another study found that high school students who worked $>10$ hours per week had less time for sports participation and exercise. ${ }^{22}$ In a study of 15-17-year-old girls, however, the girls who worked $>10$ hours per week were more active in their leisure time compared with

Table 4. Self-Reported Mean or Percent (SE) for Sedentary Activities by Employment Status

\begin{tabular}{|c|c|c|c|c|}
\hline Variable & $\mathrm{n}$ & Nonemployed & Employed & $\mathrm{p}$ value \\
\hline \multicolumn{5}{|l|}{ Total group ${ }^{\mathrm{a}}$} \\
\hline$\geq 4$ 30-minute blocks electronic media & 1381 & $41.7 \%(2.0)$ & $20.2 \%(2.0)$ & $<0.001$ \\
\hline No. of 30-minute blocks homework & 1381 & $1.9(0.1)$ & $1.6(0.1)$ & $<0.01$ \\
\hline \multicolumn{5}{|l|}{ White $^{\mathrm{b}}$} \\
\hline$\geq 4$ 30-minute blocks electronic media & 606 & $36.4 \%(2.8)$ & $18.4 \%(2.7)$ & $<0.001$ \\
\hline No. of 30-minute blocks homework & 606 & $2.3(0.2)$ & $1.9(0.2)$ & 0.01 \\
\hline \multicolumn{5}{|l|}{ African American ${ }^{\mathrm{b}}$} \\
\hline$\geq 4$ 30-minute blocks electronic media & 775 & $46.2 \%(2.5)$ & $22.3 \%(2.6)$ & $<0.001$ \\
\hline No. of 30-minute blocks homework & 775 & $1.6(0.1)$ & $1.4(0.1)$ & 0.12 \\
\hline
\end{tabular}

aMixed analyses, controlled for group, race, BMI, with school as a random variable.

${ }^{b}$ Mixed analyses, controlled for group, BMI, with school as a random variable. 
Table 5. Mean or Percent (SE) for Self-Reported Health-Relataed Variables and Employment Status

\begin{tabular}{|c|c|c|c|c|}
\hline Variable & $\mathrm{n}$ & Nonemployed & Employed & $\mathrm{p}$ value \\
\hline \multicolumn{5}{|l|}{ Total group ${ }^{a}$} \\
\hline BMI & 1381 & $24.6(0.2)$ & $25.2(0.2)$ & 0.07 \\
\hline CES-D & 952 & $14.4(0.5)$ & $14.4(0.5)$ & 0.94 \\
\hline PWC170 $\mathrm{kg} \cdot \mathrm{m} / \mathrm{min} / \mathrm{kg}$ & 906 & $11.7(0.2)$ & $11.3(0.2)$ & 0.18 \\
\hline Smoked during past 30 days & 1071 & $17.4 \%(1.8)$ & $18.5 \%(1.8)$ & 0.60 \\
\hline Sport participant in last year & 1359 & $54.9 \%(2.2)$ & $53.25(2.2)$ & 0.51 \\
\hline \multicolumn{5}{|l|}{ White ${ }^{b}$} \\
\hline BMI & 606 & $23.3(0.3)$ & $23.7(0.3)$ & 0.30 \\
\hline CES-D & 411 & $13.9(0.7)$ & $13.2(0.7)$ & 0.45 \\
\hline PWC170 kg $\cdot \mathrm{m} / \mathrm{min} / \mathrm{kg}$ & 412 & $12.5(0.3)$ & $12.1(0.3)$ & 0.28 \\
\hline Smoked during past 30 days & 459 & $23.6 \%(3.6)$ & $27.9 \%(3.5)$ & 0.29 \\
\hline Sport participant in last year & 594 & $63.9 \%(3.2)$ & $58.6 \%(3.1)$ & 0.18 \\
\hline \multicolumn{5}{|l|}{ African American ${ }^{b}$} \\
\hline BMI & 775 & $25.9(0.4)$ & $26.7(0.4)$ & 0.13 \\
\hline CES-D & 541 & $14.9(0.6)$ & $15.4(0.70$ & 0.62 \\
\hline PWC170 $\mathrm{kg} \cdot \mathrm{m} / \mathrm{min} / \mathrm{kg}$ & 494 & $11.0(0.3)$ & $10.7(0.3)$ & 0.46 \\
\hline Smoked during past 30 days & 612 & $10.1 \%(1.8)$ & $9.1 \%(1.9)$ & 0.67 \\
\hline Sport participant in last year & 765 & $46.2 \%(3.2)$ & $47.0 \%(3.3)$ & 0.82 \\
\hline
\end{tabular}

${ }^{a}$ Controlled for group, race, BMI (except PWC-170).

${ }^{b}$ Controlled for group, BMI (except PWC-170).

girls who worked fewer hours. ${ }^{6}$ Results from the current study suggest that girls who work are more physically active and that work itself can be a significant source of physical activity.

In the present study, there was no significant difference in the amount of VPA as measured by accelerometry between employed and nonemployed girls. This suggests that both employed and nonemployed girls may have participated in sports and other active leisure pursuits. Nationally, employed high school seniors spend $40 \%$ of their earnings on personal items, which includes recreation. ${ }^{1}$ As suggested by Feldman et al., ${ }^{8}$ the money that girls earned may have provided opportunities to be active.

Similarly, in the present study, no differences were found for several health indicators by employment status. Analyses were performed for the total group and separately by race. Nationally, more white high school students than African American students work. ${ }^{1,2}$ In the current study, slightly more white girls worked than African American girls, but the difference was not significant. Similar patterns were seen in both race groups in the analyses. This suggests that the influence of work on physical activity and the health behaviors studied does not differ by race. An increased risk of smoking has been found with $>10$ hours of employment per week, ${ }^{5,6}$ but Valois et al. ${ }^{3}$ did not find a relationship between smoking and the number of hours spent working in high school girls from South Carolina. In the present study, girls who reported working $>10$ 30-minute blocks on average over the 3-day period did not differ as to smoking, participation in sports over the past year, or mean BMI, CES-D, or fitness from girls who reported $<1030$-minute blocks of work.

Employed girls were 1.37 times (95\% confidence interval $[95 \% \mathrm{CI}]=1.10-1.67)$ more likely to report $<4$ blocks of EM compared with nonemployed girls. Nationally, African American high school girls report higher amounts of television and computer use than white girls. ${ }^{9}$ In the current study, more (about 10\%) nonemployed African American girls reported 4 or more 30-minute blocks of EM used than white girls, but there was a smaller difference (about $4 \%$ ) for reported EM use between African American girls and white girls who worked. Nonemployed white girls reported more homework compared with employed white girls, but there was no difference in reported 30-minute blocks of homework between nonemployed and employed African American girls.

It has been recommended that all children and youth should participate in 60 minutes of MVPA on most days of the week..$^{23}$ Recently, the Council on Sports Medicine and Fitness and Council on School Health ${ }^{24}$ stated that MVPA may be accumulated from a wide variety of activities that include sports, recreation, transportation, chores, work, planned exercise, and school-based physi- 
cal education classes. In the present study, physical activity while at work contributed to the total amount of physical activity that girls accumulated during a day. Many studies in youth have measured only leisure time physical activity, but as objective measures of physical activity become more common, questionnaires that elicit information about how youth accumulate activity, such as through chores, yard work, and types of sports, and whether they have a part-time job may be needed. Such information may be especially important in a longitudinal study to determine how types of physical activity change over time, and multiple assessment methods may be important, particularly for certain age groups.

Limitations of this study include the use of cross-sectional data, the assignment of employment status based on only 3 days of employment data, and the fact that only self-report data for physical activity were available for a majority of the girls. Because it is possible that a girl worked on a day that was not part of the recall, some misclassification may have occurred. Also, the total number of hours per week that the girls worked and their past history of employment were not known. Additionally, girls were only from South Carolina, and the results of this study may not be generalizable to other 12th grade girls. Strengths of the study include the large number of girls $(>1300)$, equal numbers of white and African American girls, and the availability of objective physical activity data on about $25 \%$ of the girls.

In summary, approximately $30 \%$ of the employed girls' total activity (total METs) was reported while at work. About $50 \%$ of the girls reported working on at least 1 of the 3 days for which data were collected, and $28 \%$ of them reported working before the end of the school day. Fewer employed girls in this study reported 4 or more blocks of EM per day compared with nonemployed girls. Also, employment was not associated with fitness, smoking, or depressive symptoms in 12th grade girls. In summary, employment offers girls the opportunity to earn money, get work experience, and decrease sedentary activity and may contribute to the accumulation of physical activity.

\section{ACKNOWLEDGMENTS}

We thank LaVerne Shuler for administration of the study and Gaye Groover Christmus, M.P.H., for editing the manuscript.

\section{REFERENCES}

1. Fox MA, Connolly BA, Snyder TD. Youth indicators 2005: Trends in the well-being of American youth. (NCES 2005-050). U.S. Department of Education and National Center for Education Statistics. Washington, DC: U.S. Government Printing Office, 2005.

2. Herz D, Kosanovich K. Trends in youth employment: Data from the current population survey. In: Manser M, ed. Report on the youth labor force. Washington, DC: U.S. Department of Labor, 2000:30.

3. Valois RF, Dunham ACA, Jackson KL, Waller JL. Association between employment and substance abuse behavior among public high school adolescents. J Adolesc Health 1999;25:256.

4. Wu L, Schluchter MD, Galvin DM. The relationship between employment and substance use among students aged 12 to 17. J Adolesc Health 2003;32:5.

5. Weller NF, Kelder SH, Cooper SP, Basen-Engquist K, Tortolero SR. School-year employment among high school students: Effects on academic, social, and physical functioning. Adolescence 2003;38:441.

6. Carriere G. Weekly work hours and health-related behaviors in full-time students. Health Rep 2005;16:11.

7. Zierold KM, Garman S, Anderson HA. A comparison of school performance and behaviors among working and nonworking high school students. Fam Community Health $2005 ; 28: 214$.

8. Feldman DE, Barnett T, Shrier I, Rossignol M, Abenhaim L. Is physical activity differentially associated with different types of sedentary pursuits? Arch Pediatr Adolesc Med 2003;157:797.

9. Centers for Disease Control and Prevention. Youth risk behavior surveillance-United States, 2005. Surveillance summaries, MMWR 2006;55(SS-5).

10. Rothstein D, Herz DA. Detailed look at employment of youths ages 12 to 15 . In: Manser M, ed. Report on the youth labor force. Washington, DC: U.S. Department of Labor. 2000:14.

11. Pate RR, Ward DS, Saunders RP, Felton G, Dishman RK, Dowda M. Promotion of physical activity in high school girls: A randomized controlled trial. Am J Public Health 2005;95:1582.

12. Weston AT, Petosa R, Pate RR. Validity of an instrument for measurement of physical activity in youth. Med Sci Sports Exerc 1997;29:138.

13. Pate RR, Ross R, Dowda M, Trost SG, Sirard J. Validation of a three-day physical activity recall instrument in female youth. Pediatr Exerc Sci 2005;15:257.

14. Ainsworth BE, Haskell WL, Whitt MC, et al. Compendium of physical activities: An update of activity codes and MET intensities. Med Sci Sports Exerc 2000;32(Suppl 9):S498.

15. American Academy of Pediatrics Committee on Public Education. Children, adolescents, and television. Pediatrics 2001;107:423.

16. American Academy of Pediatrics Committee on Public Education. Media violence. Pediatrics 2001;108:1222.

17. Trost SG, Pate RR, Sallis JF, et al. Age and gender differences in objectively measured physical activity in youth. Med Sci Sports Exerc 2002;34:350. 
18. Radloff LS. The CES-D scale: A self-report depression scale for research in the general population. Appl Psychol Meas 1971;1:385.

19. Bengtsson E. The working capacity in normal children, evaluated by submaximal exercise on the bicycle ergometer and compared with adults. Acta Med Scand 1956;154:91.

20. Boreham CA, Paliczka VJ, Nichols AK. A comparison of the PWC170 and 20-MST tests of aerobic fitness in adolescent schoolchildren. J Sports Med Phys Fitness 1990;30:19.

21. Mahoney C. 20-MST and PWC170 validity in nonCaucasian children in the U.K. Br J Sports Med 1992;26:45.

22. Safron DJ, Schulenberg JE, Bachman JG. Part-time work and hurried adolescence: The links among work intensity, social activities, health behaviors, and substance use. J Health Soc Behav 2001;42:425.
23. Strong WB, Malina RM, Blimkie CJ, et al. Evidencebased physical activity for school-aged youth. J Pediatr 2005;146:732.

24. Council on Sports Medicine and Fitness and Council on School Health. Active healthy living: Prevention of childhood obesity through increased physical activity. Pediatrics 2006;117:1834.

Address reprint requests to: Marsha Dowda, Dr.P.H. Department of Exercise Science Arnold School of Public Health 921 Assembly Street University of South Carolina Columbia, SC 29208

E-mail: mdowda@gwm.sc.edu 